\title{
Music Therapy Using Singing Training Improves Psychomotor Speed in Patients with Alzheimer's Disease: A Neuropsychological and fMRI Study
}

\author{
Masayuki Satoh $^{a}$ Toru Yuba $^{b}$ Ken-ichi Tabei ${ }^{a}$ Yukari Okubo $^{b}$ \\ Hirotaka Kida ${ }^{a}$ Hajime Sakumac Hidekazu Tomimoto ${ }^{a}$ \\ Departments of a Dementia Prevention and Therapeutics, Graduate School of Medicine, \\ ${ }^{b}$ Music, Faculty of Education and ' Radiology, Graduate School of Medicine, Mie University, \\ Tsu, Japan
}

\section{Key Words}

Music therapy · Singing training · Psychomotor speed · Behavioral and psychological symptoms of dementia - Functional magnetic resonance imaging

\section{Abstract}

Background/Aims: To investigate the effect of singing training on the cognitive function in Alzheimer's disease (AD) patients. Methods: Ten AD patients (mean age 78.1 years) participated in music therapy using singing training once a week for 6 months (music therapy group). Each session was performed with professional musicians using karaoke and a unique voice training method (the YUBA Method). Before and after the intervention period, each patient was assessed by neuropsychological batteries, and functional magnetic resonance imaging (fMRI) was performed while the patients sang familiar songs with a karaoke device. As the control group, another 10 AD patients were recruited (mean age 77.0 years), and neuropsychological assessments were performed twice with an interval of 6 months. Results: In the music therapy group, the time for completion of the Japanese Raven's Colored Progressive Matrices was significantly reduced $(p=0.026)$, and the results obtained from interviewing the patients' caregivers revealed a significant decrease in the Neuropsychiatric Inventory score $(p=0.042)$ and a prolongation of the patients' sleep time $(p=0.039)$. The fMRI study revealed increased activity in the right angular gyrus and the left lingual gyrus in the before-minusafter subtraction analysis of the music therapy intervention. Conclusion: Music therapy intervention using singing training may be useful for dementia patients by improving the neural efficacy of cognitive processing. 
Satoh et al.: Music Therapy Using Singing Training Improves Psychomotor Speed in Patients with Alzheimer's Disease: A Neuropsychological and fMRI Study

\section{Introduction}

Music therapy is defined by the World Federation of Music Therapy as the use of music and/or its musical elements (sound, rhythm, melody and harmony) by a qualified music therapist, with a client or group, in a process designed to facilitate and promote communication, relationships, learning, mobilization, expression, organization and other relevant therapeutic objectives in order to meet physical, emotional, mental, social and cognitive needs [1]. Music therapy is one of the nonpharmaceutical treatments for patients with dementia that is utilized in the daily activities of many hospitals and nursing homes. Among the nonpharmaceutical therapies for dementia, the positive effects of aerobic physical exercise have been well established. In the clinical practice guidelines for dementia, edited by Societas Neurologica Japonica [2], aerobic exercise is given a grade B recommendation, meaning it is 'recommended because of its scientific evidence'. In the same guidelines, music therapy is ranked as grade C1 (recommended, although there is no scientific evidence) [3]. The 2011 Cochrane Review of 10 randomized controlled trials on music therapy for people with dementia determined that, because of the poor methodologies used in the reported literature, it was impossible to do a meta-analysis and draw any solid conclusions about its efficacy [4]. Though music therapy is often used in many hospitals and nursing homes, there is a clear lack of scientific evidence [5]. More studies using appropriate methodologies and an understanding of the precise effects music therapy has on cognitive processing are greatly needed.

Karaoke was invented in Japan about half a century ago and has now become a worldwide form of music recreation. It is a way of singing with automatically played recorded accompaniment; in Japanese, 'kara' and 'oke' mean 'empty' and 'orchestra', respectively. Most people are very familiar with karaoke, regardless of their sex, age, or generation. During singing with the accompaniment, participants listen to the accompaniment and their own voice, and judge the gap between them to control singing [6]. All of these steps are performed unconsciously, effortlessly, and at the same time. When treating dementia patients, continual intervention is very important for both pharmaceutical and nonpharmaceutical therapies. Even if an intervention is highly effective, patients will not likely continue the therapy if the task is exhausting, boring, or uninteresting. Given that singing is a joyful and interesting task, it should be easy for patients with dementia to continually engage in the therapy using singing.

Dementia impairs a patient's abilities gradually and ruthlessly. Patients and their families are faced with the reality of increasing disability, and experience this loss from the onset of the disease. If patients can acquire a new skill through intervention, for example, singing better through voice training, the positive experience of acquisition will please and encourage them, providing the motivation to continue to participate in that activity. The satisfaction gained by acquiring a new skill, after such a long time without improvement, might ease the patient's mind and reduce the behavioral and psychological symptoms of dementia (BPSD).

We performed a nonpharmaceutical singing-based intervention with dementia patients. This involved 6 months of singing training with karaoke and a unique voice training (the YUBA Method), and investigated the effects by neuropsychological assessments. The main outcome of the present study was a difference in the results of neuropsychological assessments between patients with and without music therapy. We also performed functional magnetic resonance imaging (fMRI) during karaoke singing before and after the intervention and detected a change in the cognitive processing of singing. 
Dementia

and Geriatric

Cognitive Disorders

Table 1. Characteristics of the patients in the music therapy and control groups

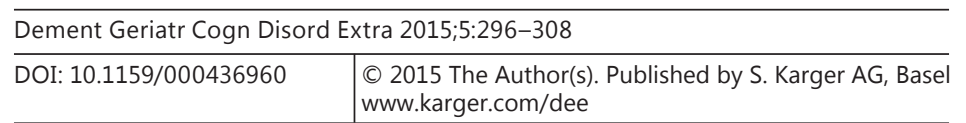

Satoh et al.: Music Therapy Using Singing Training Improves Psychomotor Speed in Patients with Alzheimer's Disease: A Neuropsychological and fMRI Study

\begin{tabular}{|c|c|c|c|c|c|}
\hline Patient No. & $\begin{array}{l}\text { Age, } \\
\text { years }\end{array}$ & Sex & $\begin{array}{l}\text { Education, } \\
\text { years }\end{array}$ & $\begin{array}{l}\text { Duration } \\
\text { of illness, } \\
\text { years }\end{array}$ & $\begin{array}{l}\text { MMSE } \\
\text { score }\end{array}$ \\
\hline \multicolumn{6}{|c|}{ Music therapy group } \\
\hline 1 & 71 & $\mathrm{~F}$ & 6 & 3 & 21 \\
\hline 2 & 74 & $\mathrm{~F}$ & 9 & 3 & 23 \\
\hline 3 & 70 & M & 16 & 2 & 24 \\
\hline 4 & 86 & $\mathrm{~F}$ & 12 & 5 & 19 \\
\hline 5 & 69 & $\mathrm{~F}$ & 16 & 4 & 13 \\
\hline 6 & 87 & M & 16 & 2 & 16 \\
\hline 7 & 85 & $\mathrm{~F}$ & 9 & 3 & 21 \\
\hline 8 & 79 & M & 18 & 3 & 19 \\
\hline 9 & 76 & $\mathrm{~F}$ & 12 & 4 & 13 \\
\hline 10 & 84 & M & 16 & 1 & 22 \\
\hline \multicolumn{6}{|c|}{ Control group } \\
\hline 1 & 71 & M & 9 & 2 & 21 \\
\hline 2 & 89 & $\mathrm{~F}$ & 10 & 3 & 17 \\
\hline 3 & 77 & $\mathrm{~F}$ & 12 & 1 & 26 \\
\hline 4 & 75 & $\mathrm{~F}$ & 9 & 3 & 22 \\
\hline 5 & 74 & $\mathrm{~F}$ & 12 & 2 & 24 \\
\hline 6 & 83 & $\mathrm{~F}$ & 12 & 4 & 18 \\
\hline 7 & 74 & $\mathrm{M}$ & 9 & 4 & 18 \\
\hline 8 & 78 & $\mathrm{~F}$ & 14 & 3 & 17 \\
\hline 9 & 68 & $\mathrm{~F}$ & 9 & 1 & 26 \\
\hline 10 & 81 & $\mathrm{~F}$ & 9 & 3 & 20 \\
\hline
\end{tabular}

\section{Subjects and Methods}

\section{Subjects}

The participants were recruited through an announcement and poster placed in our hospital. We targeted patients with mild to moderate Alzheimer's disease (AD) in order to avoid heterogeneity of symptoms. The inclusion criteria were as follows: (a) diagnosis of probable $\mathrm{AD}$ on the basis of criteria proposed by the Neurological and Communicative Disorders and Stroke-Alzheimer's Disease and Related Disorders Association (NINCDSADRDA) [7], (b) patients were able to come to our hospital once a week for the music therapy session, (c) caregivers familiar with the patient's daily life were available, (d) patients were in good general physical condition, and (e) it had been over 3 months since the use of a consistent dose of antidementia drugs. The exclusion criteria were as follows: (a) history of a cerebrovascular accident, (b) presence of a chronic disease associated with exhaustion such as malignancy and infection, (c) severe cardiac, respiratory, and orthopedic disabilities which prevent patients from participating in music therapy, (d) psychiatric symptoms that would make it impossible to perform the therapy and assessments, and (e) patients living alone with no caregiver familiar with their daily activities. We recruited 10 AD patients (ages 69-87 years, mean \pm SD $78.1 \pm 7.0$; 4 males and 6 females) all of whom were musically naïve (music therapy group). Because of the time course of recruiting, the subjects were divided into three groups: the first, second, and third group consisted of 3 (patient No. 1-3), 2 (patient No. 4 and 5), and 5 subjects (patient No. 6-10), respectively. As the control group, another $10 \mathrm{AD}$ patients were recruited (ages 68-89 years, mean \pm SD 77.0 $\pm 6.1 ; 2$ males and 8 females). These patients were willing to participate in the music therapy, but were not able due to some of the inclusion or exclusion criteria. The characteristics of each patient in the music therapy 
Satoh et al.: Music Therapy Using Singing Training Improves Psychomotor Speed in Patients with Alzheimer's Disease: A Neuropsychological and fMRI Study

Table 2. Characteristics of the music therapy and control groups

\begin{tabular}{|c|c|c|c|c|c|}
\hline & \multicolumn{2}{|c|}{ Music therapy } & \multicolumn{2}{|c|}{ Control } & \multirow{2}{*}{$\begin{array}{l}\mathrm{p} \\
\text { value }\end{array}$} \\
\hline & mean & SD & mean & SD & \\
\hline Age, years & 78.1 & 7.0 & 77.0 & 6.1 & 0.324 \\
\hline Education, years & 13.0 & 4.0 & 10.5 & 1.8 & 0.008 \\
\hline Duration of illness, years & 3.0 & 1.2 & 2.6 & 1.1 & 0.43 \\
\hline MMSE score & 19.1 & 3.9 & 20.9 & 3.5 & 0.823 \\
\hline \multicolumn{6}{|l|}{$\mathrm{RCPM}$} \\
\hline Score & 21.7 & 5.1 & 23.2 & 5.5 & 0.808 \\
\hline Time, s & 537 & 196 & 433 & 136 & 0.236 \\
\hline \multicolumn{6}{|l|}{ RBMT } \\
\hline Standard score & 5.3 & 6.7 & 6.5 & 6.1 & 0.9 \\
\hline Screening score & 1.8 & 2.2 & 2.2 & 2.4 & 0.617 \\
\hline \multicolumn{6}{|l|}{ WF, words/min } \\
\hline Animal & 7.8 & 3.7 & 9.7 & 4.6 & 0.5 \\
\hline Letter & 4.2 & 1.6 & 4.5 & 2.0 & 0.288 \\
\hline
\end{tabular}

p values were assessed by the two-sample t test; bold = significantly different.

and control groups are shown in table 1 . The only significant difference between the groups was educational history (table 2). Differences in age, intellectual function (Mini-Mental State Examination, MMSE), memory (Rivermead Behavioral Memory Test, RBMT), and frontal functions (word fluency, WF) were not significant (table 2). Every patient in both groups had taken antidementia drugs (donepezil) for $>1$ year, and participants were required not to change their pharmaceutical or other nonpharmaceutical interventions, such as the time spent participating in day care services, during the course of the study.

This study received approval from the Mie University Research Ethics Committee, and was conducted in accordance with the Declaration of Helsinki. All patients and their caregivers provided written informed consent.

\section{Methods}

\section{Music Therapy}

As an intervention, we performed group music therapy using singing training at our hospital once a week for 6 months. Two of the authors (T.Y. and Y.O.), who are a professional singer and a pianist, respectively, carried out each session for $1 \mathrm{~h}$. The sessions consisted of the following sections. First, voice training was performed for $15 \mathrm{~min}$. This involved a unique technological voice training method (the YUBA Method) which was developed by the author T.Y. $[8,9]$. The second section was a 15-min review of the former session in which the songs practiced during the previous week were sung. In the third section, participants practiced familiar songs with normal voicing for $20 \mathrm{~min}$. These songs were chosen according to their difficulty and required pitch ranges, and, as the sessions were repeated, more difficult songs were used. The last 10-min section was a so-called recreation time. The utilized songs were the patients' favorite ones, which were either popular in their youth or very familiar ones of recent years. By singing songs which they had listened to and sung when they were young, in other words, which were popular during their most productive and satisfying years, we postulate that they could experience a form of life review. For the latter three sections, a karaoke device (Joysound Crosso, Xing Inc.) was used, in addition to the keyboard. Further 
Satoh et al.: Music Therapy Using Singing Training Improves Psychomotor Speed in

details of the intervention will be closely revealed in another paper by one of the authors [T.Y., unpubl. data].

Patients in the music therapy group were also required to practice singing at home. A karaoke system (Joysound Wii Super DX, Xing Inc.) was lent to every patient. Using the system and compact disc of voice training and singing training materials, the patients were required to sing 3 times per week for 20 min each session. In general, the patients did their homework for more than the required $60 \mathrm{~min}$ per week. The caregivers were asked to report the amount of time spent doing home practice every week.

\section{Neuropsychological Assessments}

Before and after the intervention period, the following neuropsychological assessments were carried out. To measure the intellectual function, the MMSE and the Japanese Raven's Colored Progressive Matrices (RCPM) [10] were administered. The RCPM measures not only the score but also the performance time, which reflects the psychomotor speed of the subject. Memory was evaluated using the RBMT [11], which indicates memory function during daily life. The assessment of construction ability was performed based on the methods described by Strub and Black [12]. Five geometrical figures (vertical diamond, two-dimensional cross, three-dimensional block, three-dimensional pipe, and triangle within a triangle) were presented and the patient was asked to copy them one by one. Each drawing was scored by 4 possible grades (0: poor, 1: fair, 2: good, and 3: excellent), with a maximum score of 15. Frontal function was assessed by two kinds of tasks: WF and the frontal assessment battery [13]. The WF task consisted of two domains: category and letters. For the category domain, the patients were asked to name as many animals as possible within $1 \mathrm{~min}$, and for the letters WF task, we used the phonemes ka, sa, ta, and te; for each of these 4 phonemes, the patients were asked to name objects which have that phoneme at the beginning of the word [14]. The average score for these 4 phonemes was used for the statistical analysis. These neuropsychological assessments were administered to the music therapy group before and after the 6 -month music therapy intervention period. The patients of the control group also performed these assessments twice with an interval of 6 months.

It is useful to understand the state of daily life of each patient, so the caregivers were questioned before and after the music therapy intervention using the following batteries: Neuropsychiatric Inventory (NPI), Barthel Index, Instrumental Activities of Daily Living Scale (IADL), Disability Assessment for Dementia (DAD), and Zarit Burden Interview (ZBI). We also asked about the mean sleep time of both the patients and caregivers for the 2 weeks preceding the assessments. These interviews were not conducted for the control group due to time limitations and the limited opportunity for evaluation during outpatient treatment.

For the statistical analysis, a two-sample t test was used for the results obtained from the two assessments.

\section{fMRI Experiment}

In order to determine any change in brain function, we performed fMRI assessment with the music therapy group before and after the intervention period. Three popular Japanese nursery songs that were not used in the music therapy sessions were chosen. Normal karaoke images may contain actual people, scenery, and stories; therefore, we changed the background of these songs to plain blue (Joysound Wii Super DX, Xing Inc.). The patient saw only the lyrics of each song through a pair of goggles, and sang the songs with the accompaniment of the karaoke device through headphones (karaoke task). As a baseline, the patients performed the pitch task. Eight pure tones, each of which lasted $4 \mathrm{~s}$, were randomly presented via the headphones. The patients were asked to sing the same tone with the sound 'ah'. In a former study, it had been ascertained that such a task was very easy, and healthy elderly 
Satoh et al.: Music Therapy Using Singing Training Improves Psychomotor Speed in Patients with Alzheimer's Disease: A Neuropsychological and fMRI Study

people could do it immediately and effortlessly [15]. We prepared 3 sets of such stimuli. The 3 nursery songs and 3 sets of pitch stimuli were repeated 3 times. In total, each patient was asked to perform 18 blocks: 9 for the karaoke task and another 9 for the pitch task. These 18 blocks were randomly arranged and, in each block, MRI data were acquired for $24 \mathrm{~s}$. Between the serial blocks, about $30 \mathrm{~s}$ of rest were set, and the patient was then instructed on the content of the next task. The karaoke image, accompaniment, and pitch stimuli were presented using an audio-video headset delivery system (CinemaVision, Resonance Technology Inc.). Using a microphone set near the patients' mouth, we were able to monitor their performance through a speaker in the operation room.

MRI data acquisition was performed with a 3.0-tesla scanner (Achieva Quasar; Koninklijke Philips Electronics) using a T2*-weighted gradient-echo echo-planar imaging sequence (TR, 3,000 ms; TE, $35 \mathrm{~ms}$; flip angle, $90^{\circ}$; matrix size, $96 \times 96$; field of view, $240 \mathrm{~mm}$, and 168 slices with 5 -mm thickness, gapless). For the anatomical reference, MRI data were acquired using a T1-weighted turbo field-echo imaging sequence (TR, 7,600 ms; TE, $3.6 \mathrm{~ms}$; flip angle, $8^{\circ}$; field of view, $250 \times 250 \mathrm{~mm}$; slice thickness $0.7 \mathrm{~mm}$, and in-plane resolution, $1.04 \times 1.04 \mathrm{~mm}$ ).

Data were analyzed with the statistical parametric mapping program (SPM5; Wellcome Trust Center for Imaging, London, UK; http://www.fil.ion.ucl.ac.uk/spm) running on Matlab (MathWorks Inc., Natick, Mass., USA). The first echo-planar imaging data sets of each block were discarded prior to analysis to allow for T1 saturation effects. Each individual scan was realigned to the first one of each scanning condition to correct for movement artifacts. The realigned data were spatially normalized to the Montreal Neurological Institute (MNI) template and resliced at $3 \times 3 \times 3 \mathrm{~mm}$. The resulting images were smoothed with an $8-\mathrm{mm}$ (full width at half maximum) gaussian filter. Individual statistical maps (fixed effect) were calculated for the karaoke and pitch tasks and for the differences between the period before and after the music therapy intervention (main effect). Contrast images of each subject were then used for group statistics, calculated as random-effects analysis at the second level, which takes into account the variance between subjects. The statistical threshold used to report group activations was set at $\mathrm{p}<0.05$, corrected for the whole brain (false discovery rate). $t$ values were given for significant activations of the highest activated voxels for the MNI coordinates and were assigned to anatomical regions.

\section{Results}

\section{General Performance}

None of the patients in the music therapy group dropped out during the intervention period. Out of the total number of possible sessions ( 24 or 25 sessions), every patient participated more than 20 times (mean \pm SD $92.6 \pm 5.7 \%$ ). For the homework task, the mean practice time was 75 min (SD \pm 22 ) per week. Only 1 patient (No. 9) practiced less than 60 min per week (mean $44 \mathrm{~min}$ ). We determined that the participation of the patients was accomplished successfully.

\section{Neuropsychological Assessments}

The results of the neuropsychological examination before and after the music therapy intervention and during the 2 control group examinations, with an interval of 6 months, are shown in table 3 . The time to complete the RCPM significantly decreased in the music therapy group ( $p=0.026$ ) but not in the control group. The reduction in time to complete the RCPM is generally regarded as an improvement in the psychomotor speed. Other neuropsychological results from both the music therapy and control groups were not significant. The results based on interviewing caregivers about the daily lives of the patients in the music 
Dementia

and Geriatric

Table 3. Results of neuropsychological assessments in the music therapy and control groups

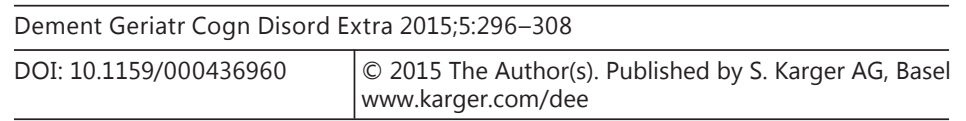

Satoh et al.: Music Therapy Using Singing Training Improves Psychomotor Speed in Patients with Alzheimer's Disease: A Neuropsychological and fMRI Study

\begin{tabular}{|c|c|c|c|c|c|c|}
\hline & \multicolumn{3}{|c|}{ Music therapy group } & \multicolumn{3}{|c|}{ Control group } \\
\hline & mean & SD & $\begin{array}{l}\mathrm{p} \\
\text { value }\end{array}$ & mean & SD & $\begin{array}{l}\mathrm{p} \\
\text { value }\end{array}$ \\
\hline \multicolumn{7}{|c|}{ MMSE score } \\
\hline Before & 19.1 & 3.9 & 0.438 & 20.9 & 3.5 & 0.678 \\
\hline After & 18.2 & 6.6 & & 20.7 & 3.9 & \\
\hline \multicolumn{7}{|l|}{ RCPM } \\
\hline \multicolumn{7}{|l|}{ Score } \\
\hline Before & 21.7 & 5.1 & 0.388 & 23.2 & 5.5 & 0.307 \\
\hline After & 20.0 & 7.9 & & 24.6 & 4.4 & \\
\hline \multicolumn{7}{|l|}{ Time, s } \\
\hline Before & 537 & 196 & 0.026 & 434 & 136 & 0.536 \\
\hline After & 396 & 116 & & 463 & 154 & \\
\hline \multicolumn{7}{|l|}{ RBMT } \\
\hline \multicolumn{7}{|c|}{ Standard score } \\
\hline Before & 5.3 & 6.7 & 0.39 & 6.5 & 6.1 & 0.209 \\
\hline After & 4.6 & 6.3 & & 5.0 & 6.1 & \\
\hline \multicolumn{7}{|c|}{ Screening score } \\
\hline Before & 1.8 & 2.2 & 0.434 & 2.2 & 2.4 & 0.496 \\
\hline After & 1.5 & 2.5 & & 1.9 & 3.0 & \\
\hline \multicolumn{7}{|c|}{ WF, words/min } \\
\hline \multicolumn{7}{|c|}{ Animal } \\
\hline Before & 7.8 & 3.7 & 0.749 & 9.7 & 4.6 & 0.083 \\
\hline After & 8.2 & 3.9 & & 8.3 & 3.7 & \\
\hline \multicolumn{7}{|l|}{ Letters } \\
\hline Before & 4.2 & 1.6 & 0.788 & 4.5 & 2.0 & 0.541 \\
\hline After & 4.3 & 2.3 & & 4.2 & 1.5 & \\
\hline
\end{tabular}

$\mathrm{p}$ values were assessed by the two-sample t test; bold = significantly improved.

therapy group revealed a significant decrease in the NPI score $(p=0.042)$ and a prolongation of the patients' sleep time $(p=0.039)$ (table 4$)$. This suggested an overall improvement in BPSD. There was also a significant decrease in the DAD score $(p=0.002)$. The change in the Barthel Index was not significant, although a decreasing trend was evident $(p=0.064)$. The latter two changes suggested that the ability of patients to perform activities of daily living had worsened over the past 6 months.

During open discussions with the interviewer, the caregivers described their impression of the changes which appeared after the beginning of the music therapy. The main effects of the music therapy which the caregivers perceived were volition, sociality, emotion, and delusion. For example, the patients voluntarily practiced singing at home. Moreover, the patients would give their opinion clearly, and often tell a joke. One patient (No. 7) who could not operate his cell phone for a year regained the ability to use it again. Another caregiver told of a patient (No. 6) who had forgotten his daughter's name for a long time, but was able to remember it and call her name again. The caregivers also reported that they felt changes within themselves. They were pleased with seeing that the patients enjoyed and tried hard at singing. This most unanimous opinion was shared by 7 caregivers. Since the onset of their illness, the patients experienced, and the caregivers watched, the continual and gradual loss of their abilities. During the course of the music therapy, however, the caregivers were very pleased and encouraged by watching the patients acquire a new skill and make progress in singing. 


\begin{tabular}{l|l}
\hline DOI: 10.1159/000436960 & $\begin{array}{l}\text { C } 2015 \text { The Author(s). Published by S. Karger AG, Basel } \\
\text { www.karger.com/dee }\end{array}$ \\
\hline
\end{tabular}

Satoh et al.: Music Therapy Using Singing Training Improves Psychomotor Speed in Patients with Alzheimer's Disease: A Neuropsychological and fMRI Study

Table 4. Changes in daily life of the patients from the music therapy group based on interviews with the caregivers

\begin{tabular}{|c|c|c|c|}
\hline & Mean & SD & $\mathrm{p}$ value \\
\hline \multicolumn{4}{|l|}{ NPI } \\
\hline Before & 8.0 & 6.3 & 0.042 \\
\hline After & 3.2 & 2.3 & \\
\hline \multicolumn{4}{|c|}{ Barthel Index } \\
\hline Before & 95.0 & 8.2 & 0.064 \\
\hline After & 88.5 & 9.4 & \\
\hline \multicolumn{4}{|l|}{ IADL } \\
\hline Before & 4.1 & 2.2 & 0.111 \\
\hline After & 3.4 & 1.8 & \\
\hline \multicolumn{4}{|l|}{ DAD } \\
\hline Before & 24.9 & 8.2 & 0.002 \\
\hline After & 20.1 & 9.4 & \\
\hline \multicolumn{4}{|l|}{$\mathrm{ZBI}$} \\
\hline Before & 20.6 & 13.2 & 0.312 \\
\hline After & 16.3 & 11.6 & \\
\hline \multicolumn{4}{|c|}{ Sleep time, $\mathrm{h}$} \\
\hline \multicolumn{4}{|c|}{ Patients } \\
\hline Before & 7.5 & 1.0 & 0.039 \\
\hline After & 8.2 & 1.4 & \\
\hline \multicolumn{4}{|c|}{ Caregivers } \\
\hline Before & 6.7 & 1.1 & 0.522 \\
\hline After & 6.9 & 0.9 & \\
\hline
\end{tabular}

\section{fMRI Study}

We realized that performance of activation studies in patients with dementia was more difficult than expected. The patients often could not understand the tasks and forgot the instructions presented only 10-15 s prior. Some patients refused the experiment itself, or panicked when his/her body was placed into the narrow space of the MRI device. As a result, only 6 patients could perform the karaoke task, and 3 the pitch task, before and after the music therapy intervention; these data were utilized for analysis. It was noteworthy that 2 patients could not perform the tasks before the intervention period, but 6 months later, they were able to do so. Patient No. 6 could not perform both the karaoke and pitch tasks before the intervention, but was able to accomplish the karaoke task after the 6 months. Patient No. 8 could only do the karaoke task at the beginning, but could perform both tasks after the intervention period.

The results of the difference in the activation maps during the karaoke task for the subtraction calculation before-minus-after the music therapy intervention period are plotted in table 5, and activation sites are shown in figure 1. More than 10 active voxels are plotted. The before-minus-after calculation for the music therapy intervention revealed increased activity at the right angular gyrus and the anterior portion of the left lingual gyrus. Other comparisons, that is the after-minus-before intervention during the karaoke task, and both subtractions (before minus after and after minus before) during the pitch task revealed no significant activation. 
Satoh et al.: Music Therapy Using Singing Training Improves Psychomotor Speed in Patients with Alzheimer's Disease: A Neuropsychological and fMRI Study

Table 5. Brain regions significantly activated during the karaoke task before minus after the music therapy intervention period

\begin{tabular}{llllllll}
\hline Brain structure & Sphere & BA & x & $y$ & z & voxels & z score \\
\hline Lingual gyrus & L & 18 & -7.9 & -58 & 4.7 & 26 & 3.93 \\
Angular gyrus & R & 39 & 44 & -65 & 14 & 18 & 3.89
\end{tabular}

$\mathrm{BA}=$ Brodmann area; $\mathrm{L}=$ left; $\mathrm{R}$ = right.

\section{Discussion}

It is generally agreed that in dementia patients, procedural memory such as singing and playing instruments is preserved at least until a moderate stage of their illness [16-19]. This suggests that it is reasonable to utilize music therapy as a nonpharmaceutical intervention for dementia. The neuropsychological assessments of the present study revealed that music therapy using singing training increased psychomotor speed in people with dementia, although other cognitive functions including intellect and memory were unchanged. Singing with the accompaniment of karaoke or keyboard requires simultaneous responses and movements, such as listening to one's own voice and the accompaniment, monitoring the gap between them, and controlling the performance [20]. Training to do such a complex task might enable improved efficacy of information processing. Based on the published literature, this is the first study to show improvement in psychomotor speed using a nonpharmaceutical intervention for patients with dementia. After the 6-month intervention period, the patients' BPSD were also improved. The positive effect of music therapy on BPSD has frequently been reported in the literature [3,21-24]. The results of the present study reinforce those findings, as do the open discussions with the caregivers. We could not determine, however, whether the improvement in BPSD caused the prolongation of the patients' sleep time, or vice versa. Combined, our data lead us to conclude that singing can produce preferable changes in patients with dementia, not only in the cognitive function but also in the psychological and behavioral state of their daily lives.

However, we should be aware of the fact that the DAD and Barthel Index scores worsened. This suggested that the daily activities of the patients decreased during the 6-month intervention period, which is attributed to the progression and natural history of AD being a chronic degenerative neurological disease. It is also probable that another factor contributed to the worsening scores, namely the awareness of and sensitivity to the patients' symptoms by the caregivers. Through the weekly contact with the medical staff present at the music therapy sessions, the caregivers were made more aware of the attributes of dementia and better recognized the conditions of the patients. Thus, it is possible that their increased understanding of dementia patients made the caregivers more sensitive to subtle symptoms which had been overlooked before. The fact that the ZBI score did not change might support this opinion; if the daily activities of the patients had truly worsened, the caregivers would have been obligated to help them more and would likely feel an increased burden. Their comments made during the open discussions also did not indicate any worsening of the patients' activities in daily living over the past 6 months.

Participating in karaoke is likely to be an easy task for many people with dementia, making it suitable as a nonpharmaceutical strategy for dementia care. In a former study, one of the authors (M.S.) revealed that singing at the same pitch as a presented tone was very easy for musically naïve cognitively normal elderly people $[15,20]$. In the present fMRI experiment, more patients were able to perform the karaoke task than the pitch task. The patients began singing when they heard the introduction of a familiar song and the lyrics appeared in 

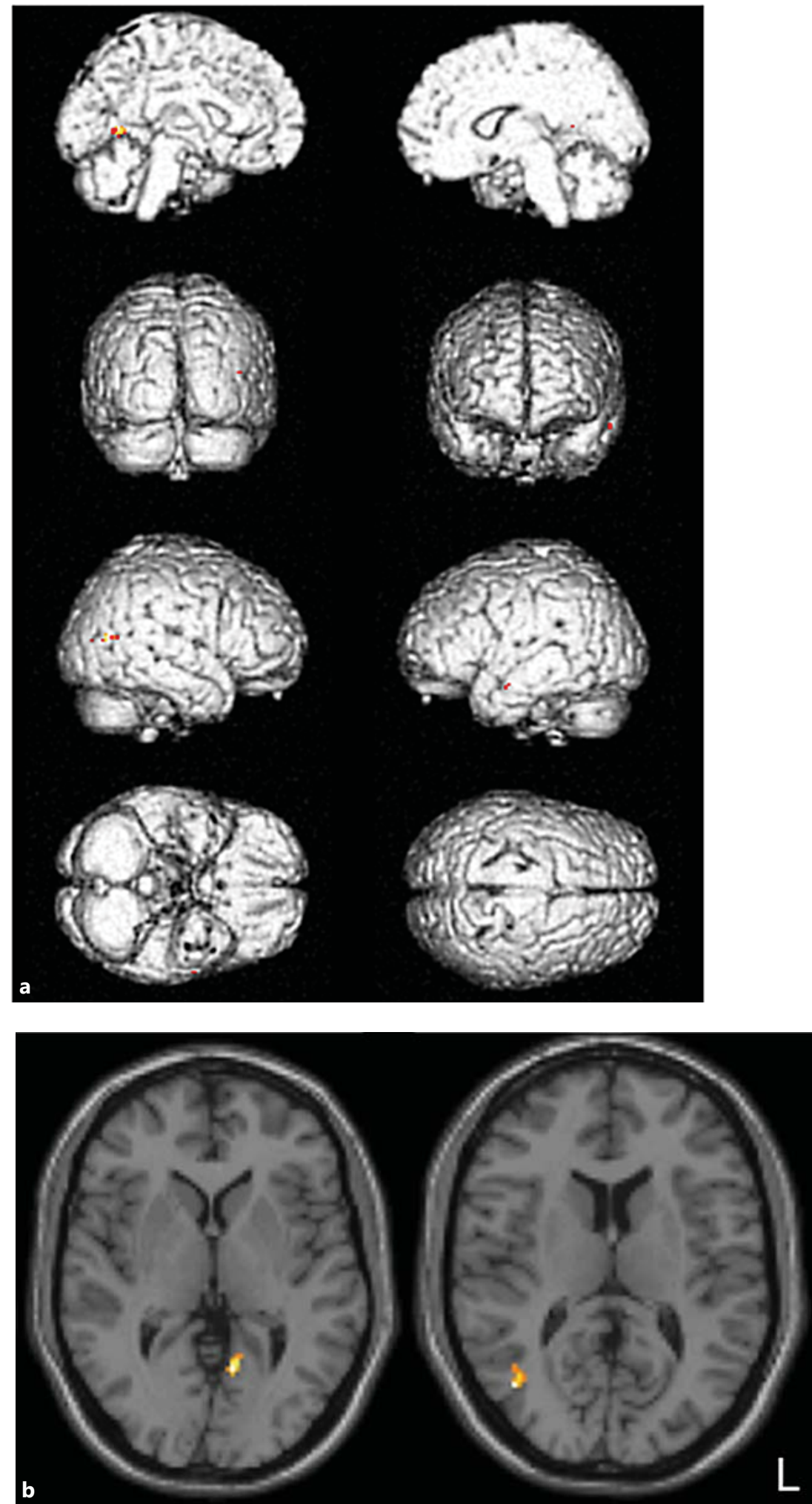

Fig. 1. Brain regions significantly activated before the music therapy intervention period compared with after the therapy. a Surface maps. b Axial images. L = Left. 
Satoh et al.: Music Therapy Using Singing Training Improves Psychomotor Speed in

the goggles, although they had difficulty remembering the instructions given by the experimenters. Performing karaoke might be a semi-involuntary task for all patients. This easiness and joyfulness might encourage patients to participate in every music therapy session and do the assigned homework. The patients who could perform neither of the tasks and those who could only do the karaoke task before the therapy were able to do the karaoke task and accomplish both tasks, respectively, after the 6-month intervention. These observations offer another confirmation of the easiness and familiarity of karaoke and the positive effects of 6 months of music therapy.

The activation of brain regions during the karaoke task, i.e. the left lingual and right angular gyrus, might be caused by reading and musical processing in the brain. The angular gyrus is known as the site of multimodal sensory integration $[25,26]$, and several studies have suggested the participation of the parietal lobe in pitch processing while listening to music and playing instruments [27-31]. Therefore, the activation of these brain regions in the present study might be congruent with the performance of karaoke, specifically the reading of lyrics, the monitoring of singing and the detection of the pitch gap between their voice and the accompaniment. An important point to note is that the activation was observed in the before-minus-after, but not in the after-minus-before, intervention period calculation. This suggested that after the intervention period, the patients were able to carry out the same task using smaller brain regions than before. The phenomenon that activated brain regions are reduced as a subject masters a task has recently been reported in the literature [32, 33], and is referred to as the 'neural efficiency theory' [32]. In our study, it is hypothesized that the patients in the music therapy group acquired a new cognitive strategy for karaoke singing.

The current study has several limitations. First, the number of subjects was relatively small. Because music therapy is usually performed in small groups, many reports on music therapy intervention in dementia patients contained fewer than 20 participants [3]. Based on the observed positive effects, we would like to apply this method to a larger number of patients. Second, there was a significant difference in the educational history between the music therapy and control groups. The possibility cannot be eliminated that the positive effects were caused by the higher education background of the music therapy group. Third, the intervention period in this study was 6 months, whereas the period of many of the studies on music therapy and dementia reported in the literature was shorter [22, 23, 34]. We are therefore unable to determine if a longer intervention will produce a greater effect or if the progression of the disease will restrict further improvement. Lastly, the present study targeted only mild to moderate AD patients. Further studies are needed to determine if this method will have the same effect on patients with severe AD or other dementia-related diseases such as dementia with Lewy bodies and vascular dementia.

\section{Conclusion}

We performed music therapy using singing training with AD patients for 6 months by means of karaoke and a unique vocal training (the YUBA Method). After the intervention period, patients showed a significant improvement in psychomotor speed and BPSD. The analysis with fMRI showed a reduction in the size of activated brain regions during the task performance, which suggested the organization of a new cognitive strategy in the brain. Singing is an easy and joyful activity, and the introduction of singing training with karaoke as well as the voice training (the YUBA Method) may provide a valuable tool for the care of dementia patients in hospitals and homes. 
Satoh et al.: Music Therapy Using Singing Training Improves Psychomotor Speed in Patients with Alzheimer's Disease: A Neuropsychological and fMRI Study

\section{Acknowledgments}

We would like to thank Mr. Takase and his colleagues at the Department of Radiology at the Mie University Hospital for their kind contribution of performing the fMRI study.

\section{Disclosure Statement}

We were offered the karaoke device and a grant from Xing Inc.

\section{References}

1 World Federation of Music Therapy. http://www.musictherapyworld.net/WFMT/FAQMusicTherapy.html.

2 Societas Neurologica Japonica: Guideline for Dementing Disorder. Tokyo, Igaku-Shoin Ltd, 2010, pp 179-180.

-3 Ueda T, Suzukamo Y, Sato M, Izumi S: Effects of music therapy on behavioral and psychological symptoms of dementia: a systematic review and meta-analysis. Ageing Res Rev 2013;12:628-641.

-4 Vink AC, Bruinsma MS, Scholten RJ: Music therapy for people with dementia. Cochrane Database Syst Rev 2011;3:CD003477.

5 Satoh M: Scientific investigations of the therapeutic effects of music therapy. Acoust Sci Technol 2013;34:1-4.

6 Satoh M: Musical processing in the brain: a neuropsychological approach through cases with amusia. Austin J Clin Neurol 2014;1:1-11.

7 McKhann G, Drachman D, Folstein M, Katzman R, Price D, Stadlan EM: Clinical diagnosis of Alzheimer's disease: report of the NINCDS-ADRDA Work Group under the auspices of Department of Health and Human Services Task Force on Alzheimer's disease. Neurology 1984;34:939-944.

-8 Yuba T, Itoh T, Kaga K: Unique technological voice method (The YUBA Method) shows clear improvement on patients with cochlear implants in singing. J Voice 2009;23:119-124.

$>9$ Yuba T, Itoh T, Yamasoba T, Kaga K: Advancement in singing ability using The YUBA Method in patients with cochlear implants. Acta Otolaryngol 2008;128:465-472.

10 Raven JC: Coloured Progressive Matrices Sets A, Ab, B. New York, Oxford Psychologists Press, 1995.

11 Wilson B, Cockburn J, Baddeley A: The Rivermead Behavioural Memory Test. Edmunds, Thames Valley Test Company, 1985.

12 Strub RL, Black FW: The Mental Status Examination in Neurology, ed 4. Philadelphia, FA Davis Company, 2000, pp 93-115.

13 Dubois B, Slachevsky A, Litvan I, Pillon B: The FAB: a frontal assessment battery at bedside. Neurology 2000; 55:1621-1626.

14 Dohi N, Iwaya T, Kayamori R: Seishin-kinou Hyouka (The Evaluation of Mental Function) (in Japanese). Tokyo, Ishiyaku Publishers Inc, 1992.

15 Satoh M, Takeda K, Murakami Y, Onouchi K, Inoue K, Kuzuhara S: A case of amusia caused by the infarction of anterior portion of bilateral temporal lobes. Cortex 2005;41:77-83.

-16 Cowles A, Beatty WW, Nixon SJ, Lutz LJ, Paulk J, Paulk K, Ross E: Musical skill in dementia: a violinist presumed to have Alzheimer's disease learns to play a new song. Neurocase 2003;9:493-503.

17 Baird A, Samson S: Memory for music in Alzheimer's disease: unforgettable? Neuropsychol Rev 2009;19: 85-101.

18 Gagnon L, Peretz I, Fülöp T: Musical structural determinants of emotional judgments in dementia of Alzheimer type. Neuropsychology 2009;23:90-97.

19 Vanstone A, Cuddy L: Musical memory in Alzheimer disease. Neuropsychol Dev Cogn B Aging Neuropsychol Cogn 2010;17:108-128.

20 Satoh M, Takeda K, Kuzuhara S: A case of auditory agnosia with impairment of perception and expression of music: cognitive processing of tonality. Eur Neurol 2007;58:70-77.

21 Livingston G, Johnston K, Katona C, Paton J, Lyketsos CG: Systematic review of psychological approaches to the management of neuropsychiatric symptoms of dementia. Am J Psychiatry 2005;162:1996-2021.

-22 Svansdottir HB, Snaedal J: Music therapy in moderate and severe dementia of Alzheimer's type: a case-control study. Int Psychogeriatr 2006;18:613-621.

-23 Raglio A, Bellelli G, Traficante D, Gianotti M, Ubezio MC, Villani D, Trabucchi M: Efficacy of music therapy in the treatment of behavioral and psychiatric symptoms of dementia. Alzheimer Dis Assoc Disord 2008;22: 158-162.

24 McDermott 0, Crellin N, Ridder HM, Orrell M: Music therapy in dementia: a narrative synthesis systematic review. Int J Geriatr Psychiatry 2013;28:781-794.

25 Geschwind N: Disconnection syndromes in animals and man. Brain 1965;88:237-294.

26 Van Hoesen GW: The modern concept of association cortex. Curr Opin Neurobiol 1993;3:150-154. 
-27 Sergent J, Zuck E, Terriah S, MacDonald B: Distributed neural network underlying musical sight-reading and keyboard performance. Science 1992;257:106-109.

-28 Satoh M, Takeda K, Nagata K, Hatazawa J, Kuzuhara S: Activated brain regions in musicians during an ensemble: a PET study. Cogn Brain Res 2001;12:101-108.

29 Satoh M, Takeda K, Nagata K, Hatazawa J, Kuzuhara S: The anterior portion of the bilateral temporal lobes participate in music perception: a PET study. Am J Neuroradiol 2003;24:1843-1848.

30 Stewart L, Henson R, Kampe K, Walsh V, Turner R, Frith U: Brain changes after learning to read and play music. Neuroimage 2003;20:71-83.

-31 Kleber B, Birbaumer N, Veit R, Trevorrow T, lotze M: Overt and imagined singing of an Italian aria. Neuroimage 2007;36:889-900.

32 Neubauer AC, Fink A: Intelligence and neural sufficiency. Neurosci Biobehav Rev 2009;33:1004-1023.

-33 Engström M, Landtblom AM, Karlsson T: Brain and effort: brain activation and effort-related working memory in healthy participants and patients with working memory deficits. Front Hum Neurosci 2013; 7:140.

-34 Guétin S, Portel F, Picot MC, Pommié C, Messaoudi M, Djabelkir L, Olsen AL, Cano MM, Lecourt E, Touchon J: Effects of music therapy on anxiety and depression in patients with Alzheimer's type dementia: randomized, controlled study. Dement Geriatr Cog Disord 2009;28:36-46. 